\title{
Reactions of an Isolable Dialkylstannylene with Carbon Disulfide and Related Heterocumulenes
}

Chenting Yan, Zheng Xu, Xu-Qiong Xiao, Zhifang Li, * Qiong Lu, Guoqiao Lai and

Mitsuo Kira*

Key Laboratory of Organosilicon Chemistry and Material Technology of Ministry of Education, Hangzhou Normal University, Hangzhou, 311121, Zhejiang, People's

Republic of China

\section{zhifanglee@hznu.edu.cn, mkira@m.tohoku.ac.jp}

\section{Supporting Information}

\section{Contents}

1. X-ray analysis of $\mathbf{8 , 9}$, and $\mathbf{1 1}$.

S - 2

2. ${ }^{1} \mathrm{H},{ }^{13} \mathrm{C}$, and ${ }^{119} \mathrm{Sn}$ NMR spectra of $\mathbf{8}, \mathbf{9}$ and $\mathbf{1 1} . \quad \mathrm{S}-3$

3. MALDI-TOFMS spectra of 8 and $9 . \quad \mathrm{S}-8$

4. The rearrangement of 8 to $9 \quad$ S - 9

5. Kinetic study of the rearrangement of 8 to $9 . \quad S-11$

6. DFT calculations $\quad \mathrm{S}-12$

7. References S -13 


\section{X-ray analysis of 8,9 and 11 .}

Molecular structure determination. Single crystals of $\mathbf{8 , 9}$ and $\mathbf{1 1}$ suitable for X-ray analysis were obtained by the recrystallization from hexane. The X-ray diffraction data were collected on a Bruker Smart Apex CCD diffractometer with graphite monochromated Mo-K $\alpha$ radiation $(\lambda=0.71073 \AA)$ using the $\omega-2 \theta$ scan mode. The structures were solved by direct methods and refined on $F 2$ by full-matrix least-squares methods using SHELX-2000. ${ }^{\mathrm{S} 1}$ Crystal and refinement data for $\mathbf{8}, \mathbf{9}$, and 11 are deposited with CCDC; CCDC Nos. are 1432785, 1432786 and 1432787, respectively.

Table S1. Crystal and Refinement Data for 8,9 and $\mathbf{1 1}$

\begin{tabular}{|c|c|c|c|}
\hline Parameters & 8 & 9 & 11 \\
\hline Empirical formula & $\mathrm{C}_{34} \mathrm{H}_{80} \mathrm{~S}_{4} \mathrm{Si}_{8} \mathrm{Sn}_{2}$ & $\mathrm{C}_{34} \mathrm{H}_{80} \mathrm{~S}_{4} \mathrm{Si}_{8} \mathrm{Sn}_{2}$ & $\mathrm{C}_{29} \mathrm{H}_{59} \mathrm{NO}_{2} \mathrm{Si}_{4} \mathrm{Sn}$ \\
\hline Formula weight & 1079.32 & 1079.32 & 684.82 \\
\hline Crystal system, Space group & Monoclinic,P2(1)/c & Triclinic, P-1 & Triclinic, P1 \\
\hline$a[\AA]$ & $11.6252(10)$ & $11.5533(12)$ & $11.545(2)$ \\
\hline$b[\AA]$ & $28.719(3)$ & $15.0410(15)$ & $11.929(3)$ \\
\hline$c[\AA]$ & $17.7048(16)$ & $17.1546(18)$ & $15.061(4)$ \\
\hline$\alpha[\mathrm{deg}]$ & 90 & $88.192(2)$ & $75.183(6)$ \\
\hline$\beta[\mathrm{deg}]$ & $108.850(2)$ & $71.330(2)$ & $67.479(3)$ \\
\hline$\gamma[\mathrm{deg}]$ & 90 & $76.698(2)$ & $76.791(4)$ \\
\hline$V\left[\AA^{-3}\right]$ & $5594.0(9)$ & $2745.5(5)$ & $1832.4(7)$ \\
\hline$Z, \quad D_{\text {calcd }}\left[\mathrm{Mg} / \mathrm{m}^{-3}\right]$ & $4,1.282$ & $2,1.306$ & $2,1.241$ \\
\hline$\mu \quad\left[\mathrm{mm}^{-1}\right]$ & 1.235 & 1.258 & 0.852 \\
\hline$F(000)$ & 2240 & 1120 & 724 \\
\hline Reflections & 30544 & 32975 & 18570 \\
\hline Independent Reflections & 9733 & 12389 & 6375 \\
\hline$R$ (int) & 0.0404 & 0.0251 & 0.0238 \\
\hline $\begin{array}{l}\text { Data/restraints } \\
\text { /parameters }\end{array}$ & $9733 / 26 / 453$ & $12389 / 0 / 457$ & $6375 / 2 / 350$ \\
\hline $\begin{array}{l}\text { final } \mathrm{R} \text { indices } \\
{[I>2 \sigma(I)] R_{I}, w R 2}\end{array}$ & $0.0486,0.1228$ & $0.0333,0.0922$ & $0.0252,0.0791$ \\
\hline$R$ indices (all data) $w R_{2}$ & $0.0735,0.1372$ & $0.0440,0.1042$ & $0.0327,0.1160$ \\
\hline
\end{tabular}


2. ${ }^{1} \mathrm{H},{ }^{13} \mathrm{C}$, and ${ }^{119} \mathrm{Sn}$ NMR spectra of 8,9 and 11 .
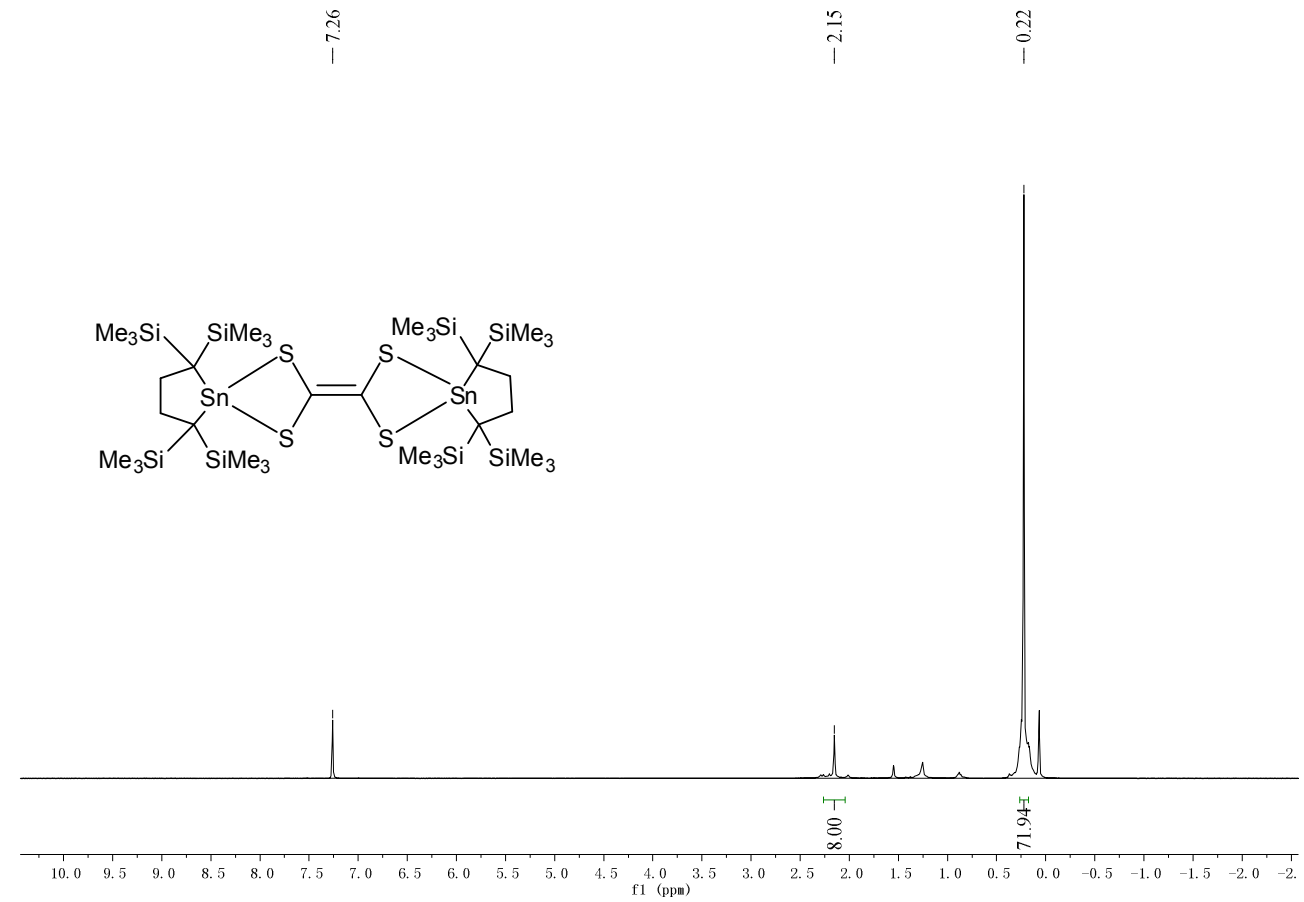

Figure S1. ${ }^{1} \mathrm{H}$ NMR spectrum of compound $\mathbf{8}$ in $\mathrm{CDCl}_{3}$.

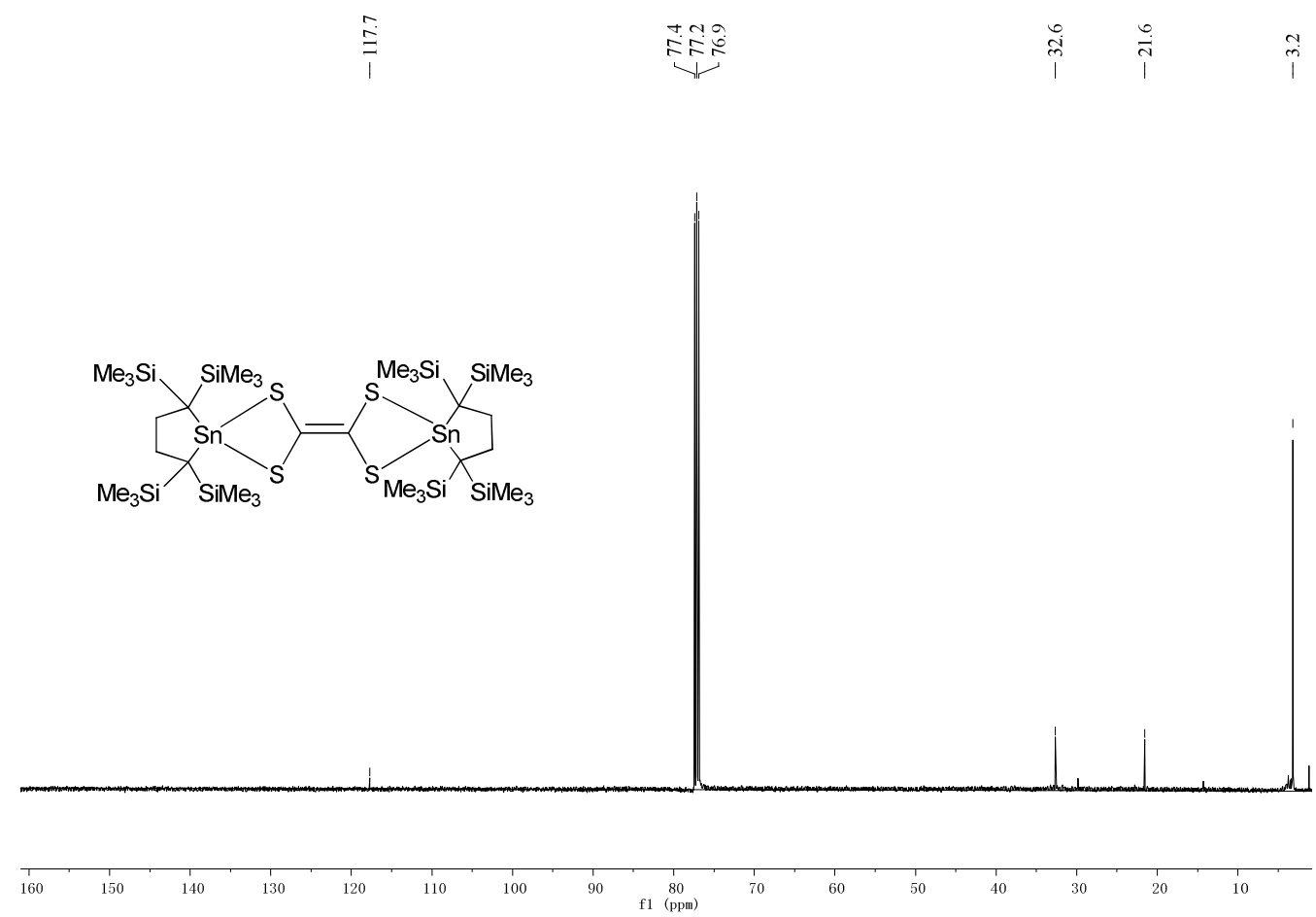

Figure S2. ${ }^{13} \mathrm{C}$ NMR spectrum of compound 8 in $\mathrm{CDCl}_{3}$. 

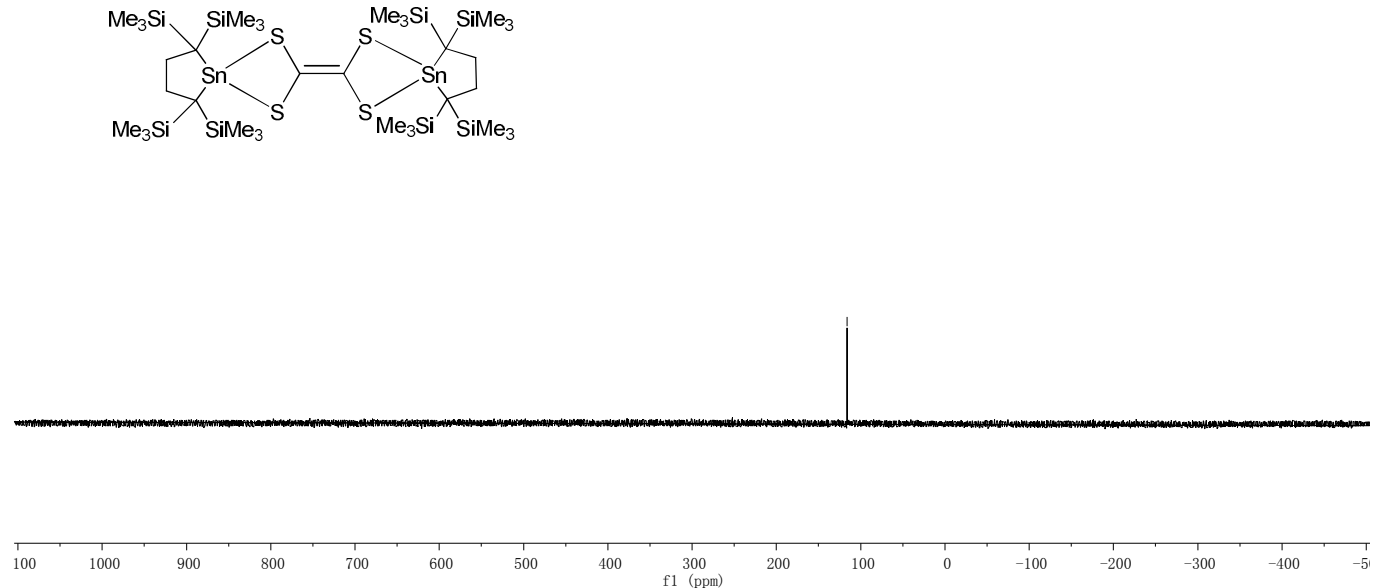

Figure S3. ${ }^{119} \mathrm{Sn}$ NMR spectrum of compound $\mathbf{8}$ in $\mathrm{CDCl}_{3}$.

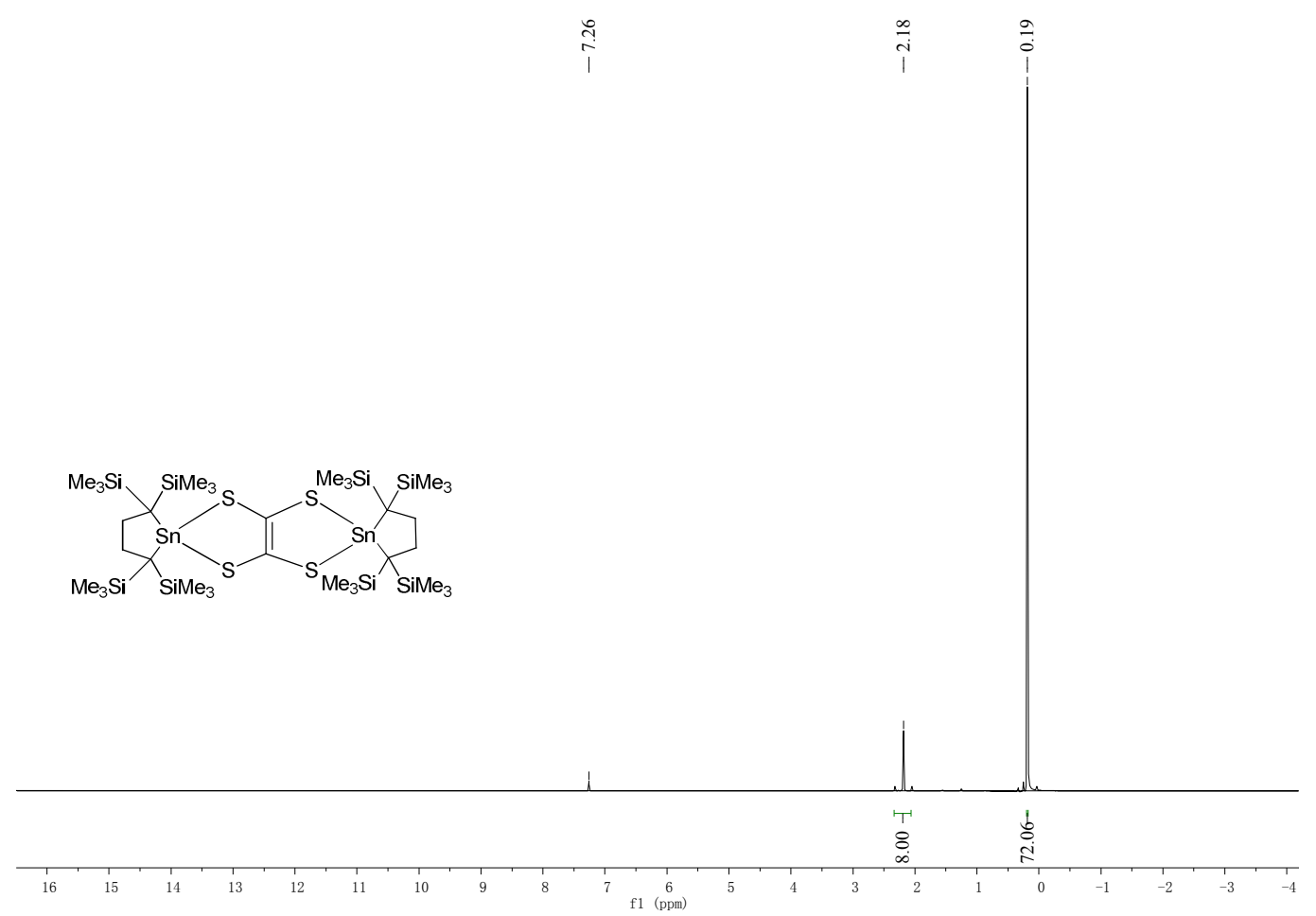

Figure S4. ${ }^{1} \mathrm{H}$ NMR spectrum of compound 9 in $\mathrm{CDCl}_{3}$. 

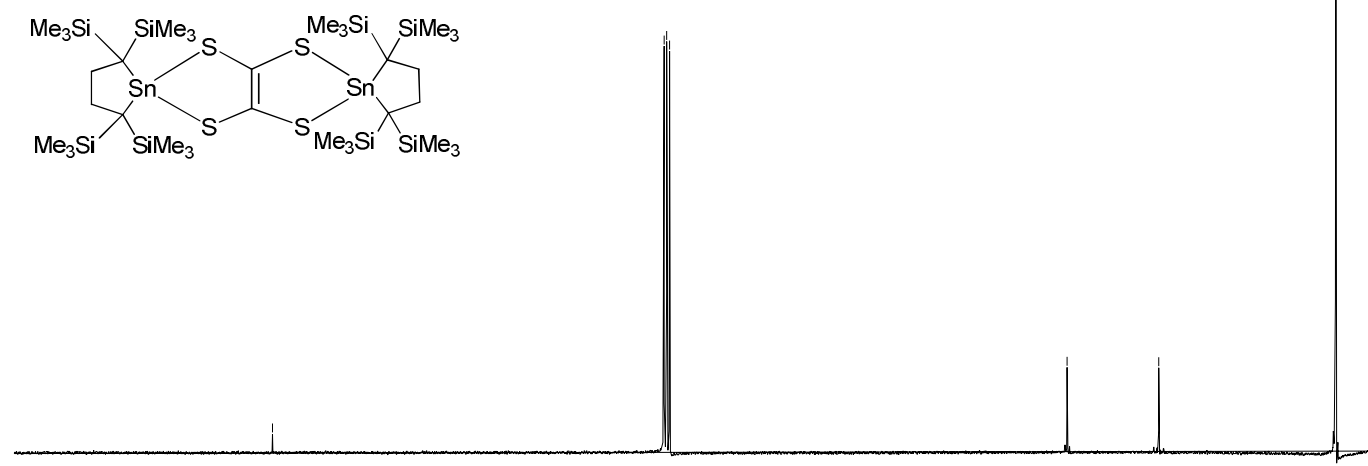

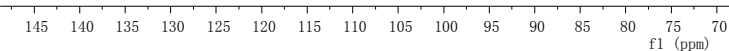

Figure S5. ${ }^{13} \mathrm{C}$ NMR spectrum of compound 9 in $\mathrm{CDCl}_{3}$.
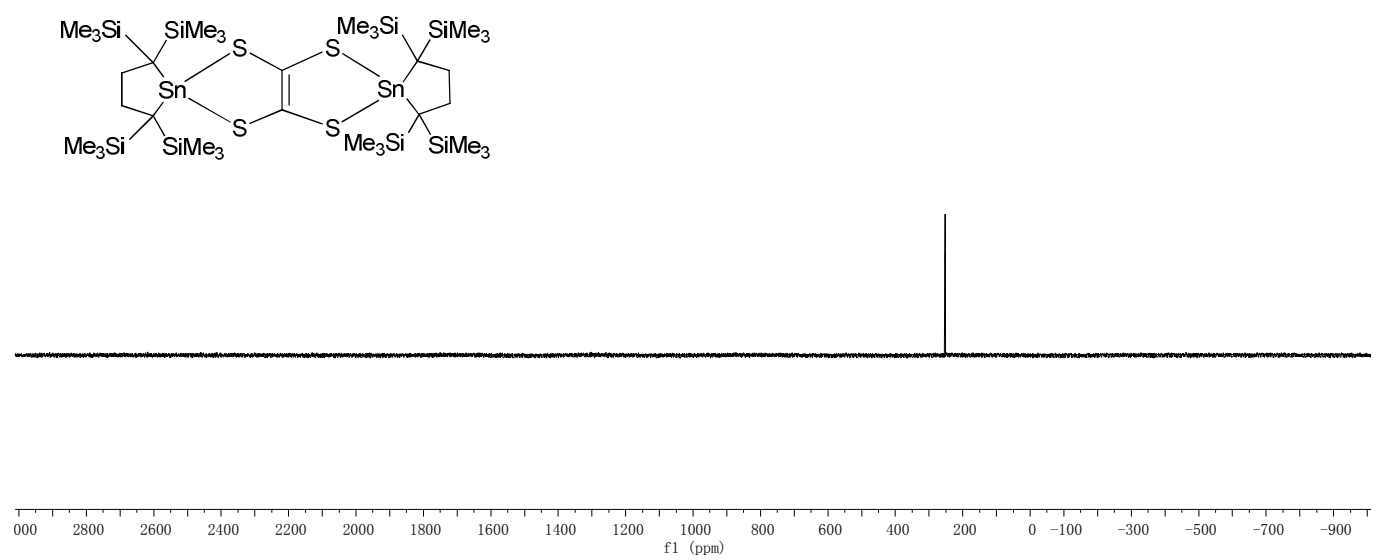

Figure S6. ${ }^{119} \mathrm{Sn}$ NMR spectrum of compound 9 in $\mathrm{CDCl}_{3}$. 

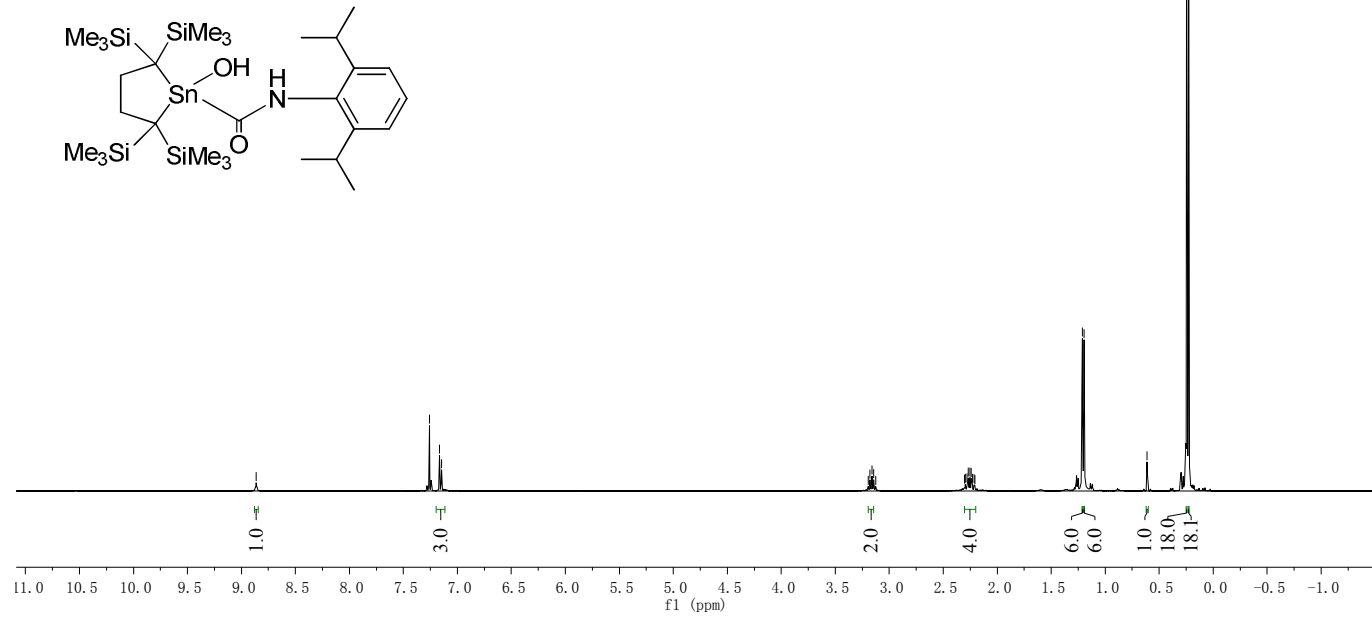

Figure S7. ${ }^{1} \mathrm{H}$ NMR spectrum of compound 11 in $\mathrm{CDCl}_{3}$.

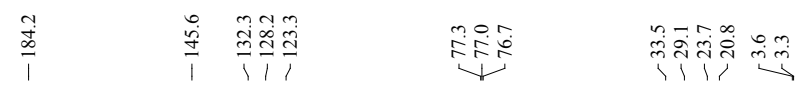

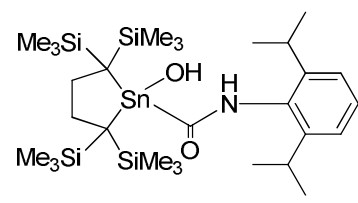

$\begin{array}{llllllllllllllllllllllllllllllllllllllllll}20 & 310 & 300 & 290 & 280 & 270 & 260 & 250 & 240 & 230 & 220 & 210 & 200 & 190 & 180 & 170 & 160 & 150 & 140 & 130 & 120 & 110 & 100 & 90 & 80 & 70 & 60 & 50 & 40 & 30 & 20 & 10 & 1\end{array}$

Figure S8. ${ }^{13} \mathrm{C}$ NMR spectrum of compound 11 in $\mathrm{CDCl}_{3}$. 

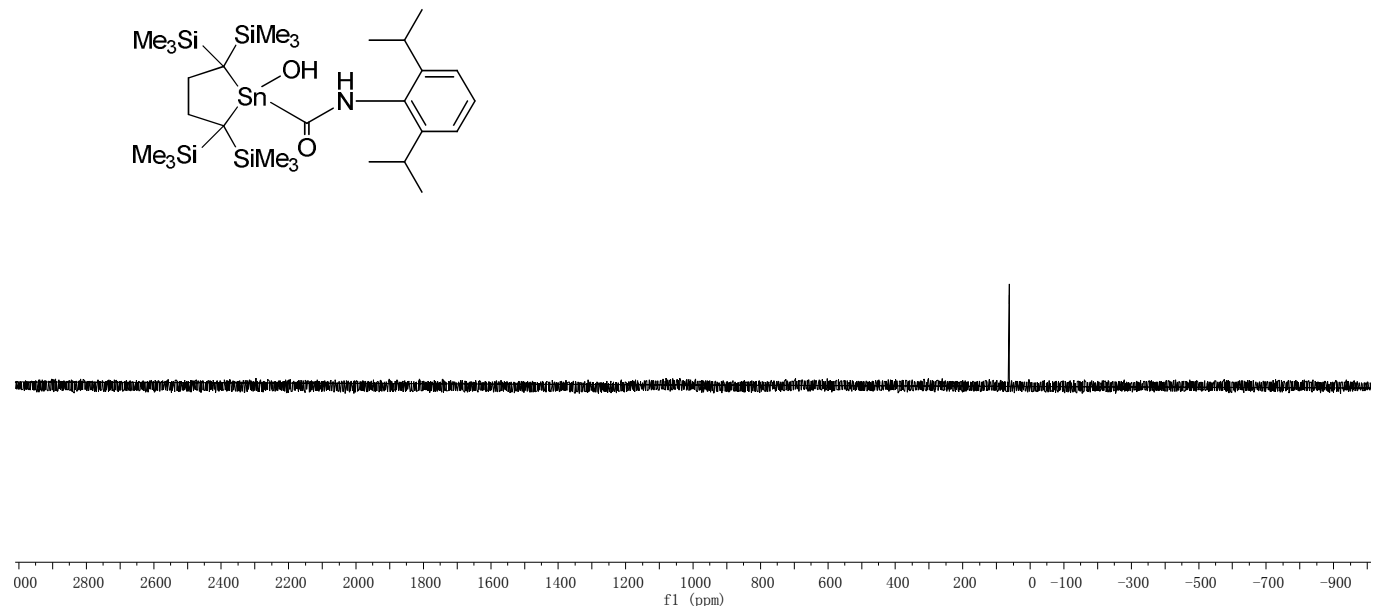

Figure S9. ${ }^{119} \mathrm{Sn}$ NMR spectrum of compound $\mathbf{1 1}$ in $\mathrm{CDCl}_{3}$. 


\section{MALDI-TOFMS spectra of 8 and 9.}

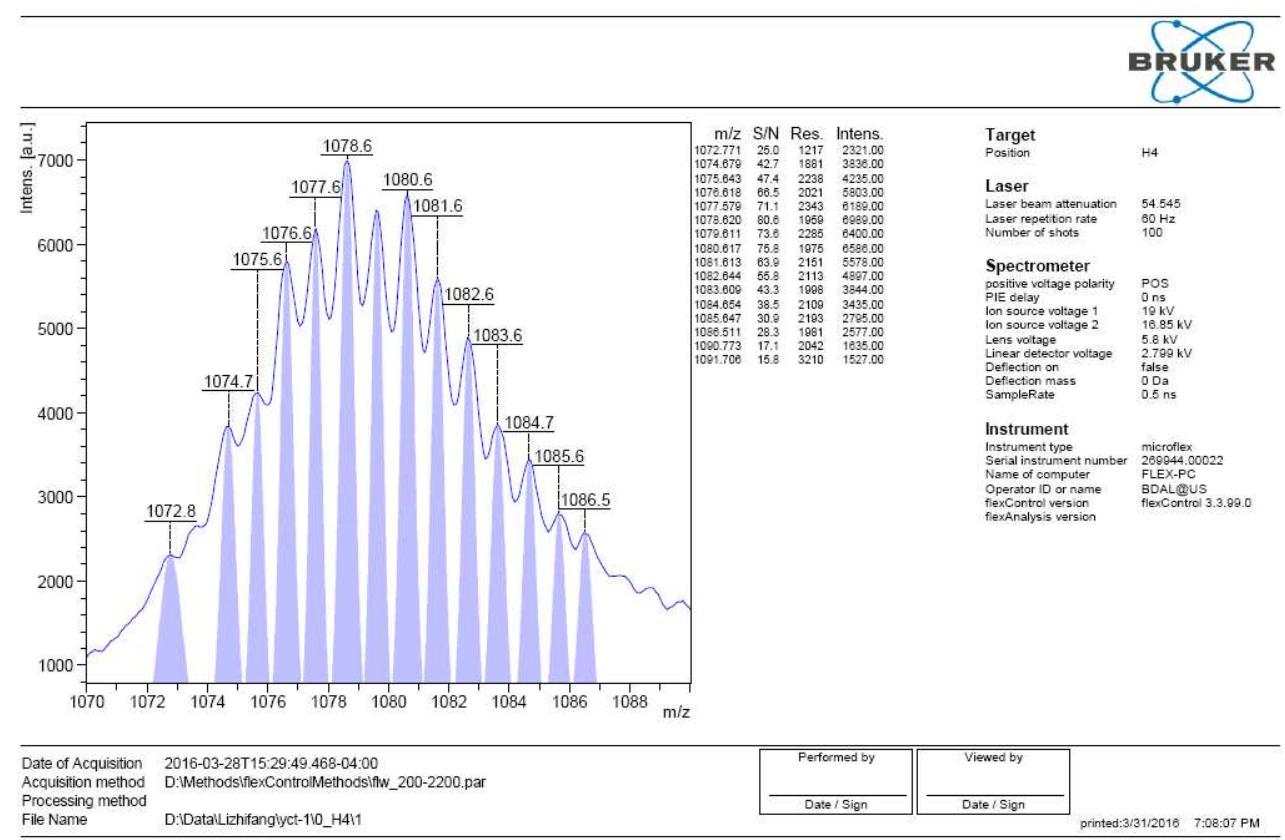

Figure S10. MALDI-TOFMS spectrum of 8 .

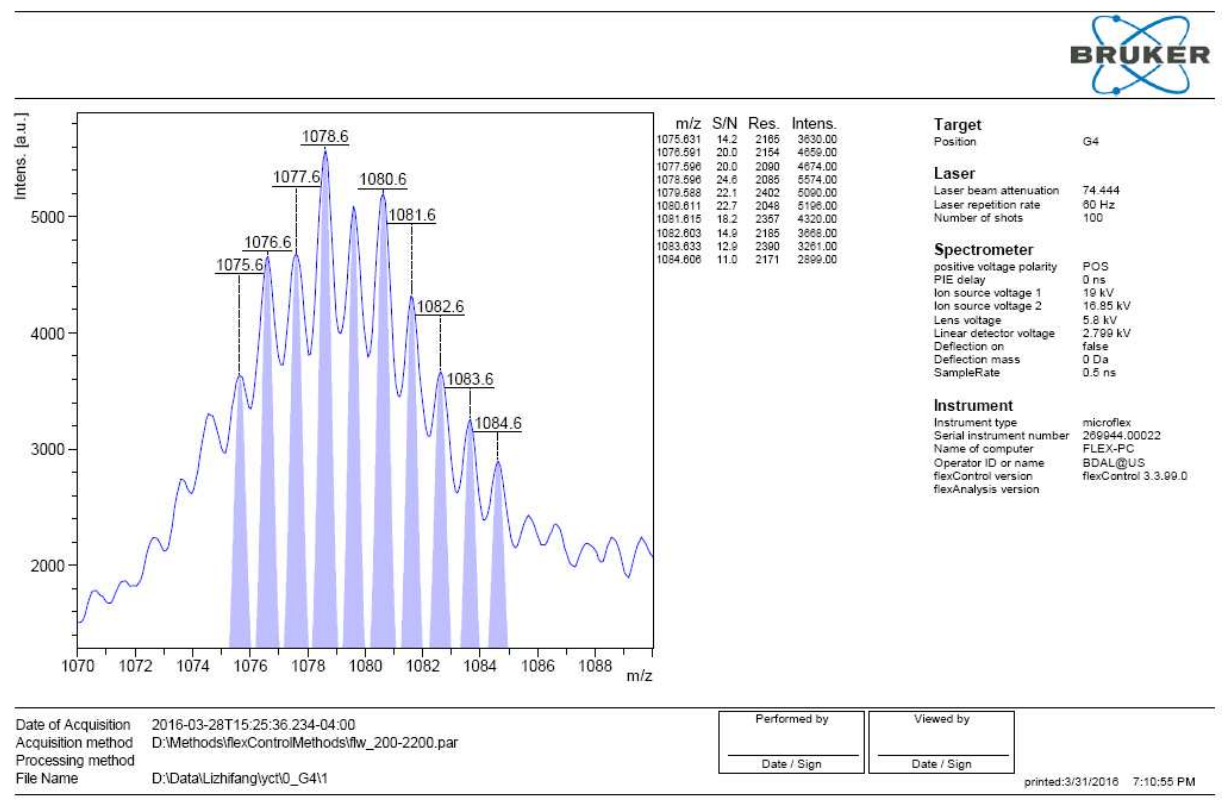

Figure S11. MALDI-TOFMS spectrum of 9. 


\section{The rearrangement of 8 into 9}

Thermal rearrangement of 8 to 9 . In an NMR tube was added compound 8 (13 mg, $0.012 \mathrm{mmol}$ ), and $\mathrm{C}_{6} \mathrm{D}_{6}(0.6 \mathrm{~mL})$ and then the mixture was stirred for $48 \mathrm{~h}$ at $100{ }^{\circ} \mathrm{C}$. The ${ }^{119} \mathrm{Sn}$ NMR spectrum showed the formation of 9 in $9 \%$ yields as shown in Figure S12.

Rearrangement of 8 to 9 catalyzed by dialkylstannylene 1. A mixture of 8 (52 mg, $0.048 \mathrm{mmol})$, dialkylstannylene 1 (20 mol\%), and hexane $(10 \mathrm{~mL})$ was stirred for $24 \mathrm{~h}$ at room temperature in a $20 \mathrm{~mL}$ flask. The solvent was removed under vacuo. The ${ }^{119} \mathrm{Sn}$ NMR spectrum of the residue in $\mathrm{CDCl}_{3}$ showed quantitative formation of 9 (Figure S13).

Rearrangement of 8 to 9 catalyzed with $\mathbf{B F}_{3}$. A mixture of $8(13 \mathrm{mg}, 0.012$ mmol), $\mathrm{CDCl}_{3}(0.6 \mathrm{~mL})$, and a catalytic amount of $\mathrm{BF}_{3}(10 \mathrm{~mol} \%)$ in an NMR tube was stirred for $30 \mathrm{~min}$ at room temperature and then the ${ }^{119} \mathrm{Sn}$ NMR spectrum was measured. Compound 9 was found to form in 92\% (Figure S14).
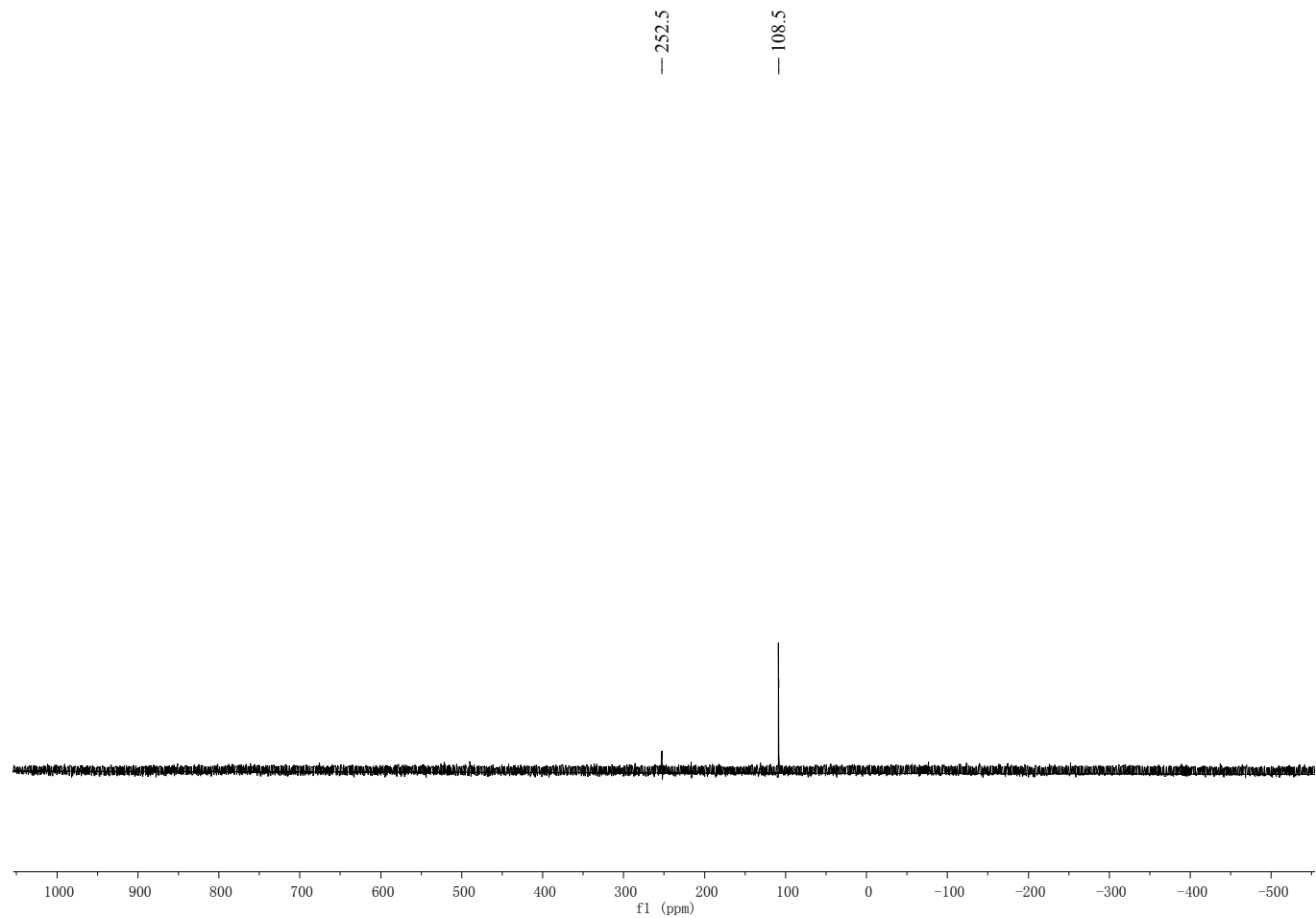

Figure S12. ${ }^{119} \mathrm{Sn}$ NMR spectrum obtained after the thermal reaction of 8 in $\mathrm{C}_{6} \mathrm{D}_{6}$. 


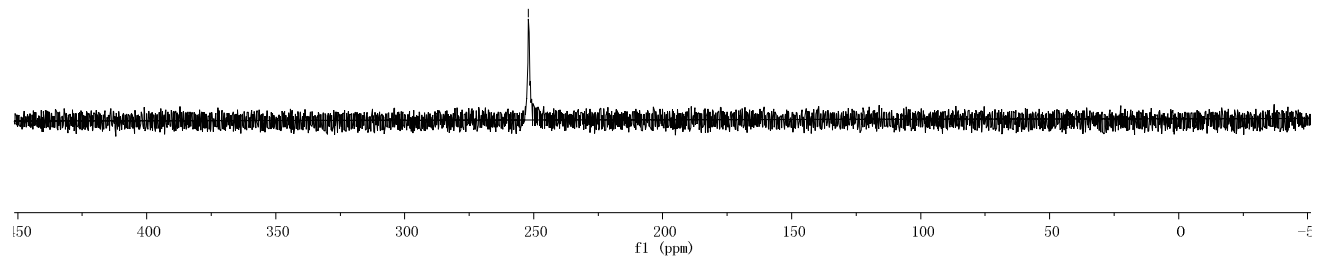

Figure S13. ${ }^{119}$ Sn NMR spectrum obtained after 8 was treated in the presence of stannylene 1 (20 $\mathrm{mol} \%$ ) in hexane at $\mathrm{rt}$ showing the quantitative formation of 9 . The NMR spectrum was measured in $\mathrm{CDCl}_{3}$.

Sn119-LZF-yct-0104-1
Sn119-LZF-yct-0104-1
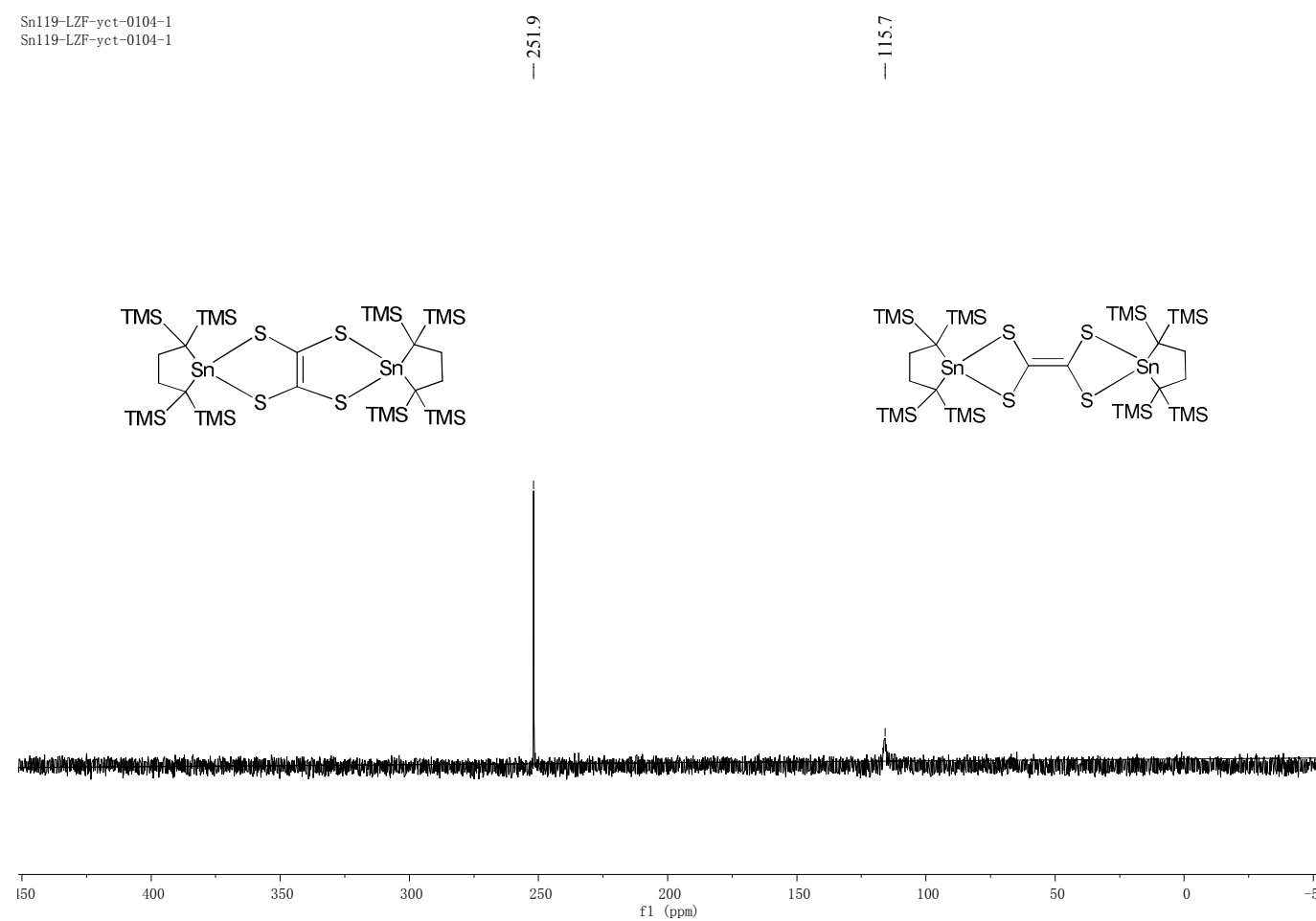

Figure S14. ${ }^{119} \mathrm{Sn}$ NMR spectrum obtained after compound 8 was treated with $\mathrm{BF}_{3}(10 \mathrm{~mol} \%)$ for 30 min in $\mathrm{CDCl}_{3}$. 
5. Kinetic study of the rearrangement of 8 to 9. For a kinetic study, a $\mathrm{C}_{6} \mathrm{D}_{6}(1$ $\mathrm{mL})$ solution of $8(50 \mathrm{mg}, 0.046 \mathrm{mmol})$ containing stannylene $\mathbf{1}(1.1 \mathrm{mg}, 5 \mathrm{~mol} \%)$ in an NMR tube was kept at $10{ }^{\circ} \mathrm{C}$ and monitored the time course of the relative ${ }^{119} \mathrm{Sn}$ NMR signal intensities of $\mathbf{8}$ and $\mathbf{9}$. The molar ratio of $\mathbf{8} /(\mathbf{8}+\mathbf{9})$ was determined using the relative NMR signal intensities of $8\left(I_{8}\right)$ and $9\left(I_{9}\right)$ by assuming the same relaxation times for the ${ }^{119} \mathrm{Sn}$ nuclei in $\mathbf{8}$ and $\mathbf{9}$. As the slope of a linear plot of $\ln \left(I_{8} /\left(I_{8}+I_{9}\right)\right.$ against reaction time $(t / \mathrm{h})$ (Figure S13), the first-order rate constant $\left(k^{\prime}\right)$ was determined as $5.2 \times 10^{-3} \mathrm{~h}^{-1}$ or $1.4 \times 10^{-6} \mathrm{~s}^{-1}$. Assuming that the rearrangement is bimolecular with the unimolecular contribution of $\mathbf{1}$, the 2 nd-order rate constant $(k)$ is estimated to be $6.3 \times 10^{-4} \mathrm{M}^{-1} \mathrm{~s}^{-1}$ at $10^{\circ} \mathrm{C}$. The assumption for the relaxation times, the significant temperature turbulence, and other minor ambiguities during the experiment make the rate constant rather inaccurate but the results support the proposed mechanism for the rearrangement (eq 8).

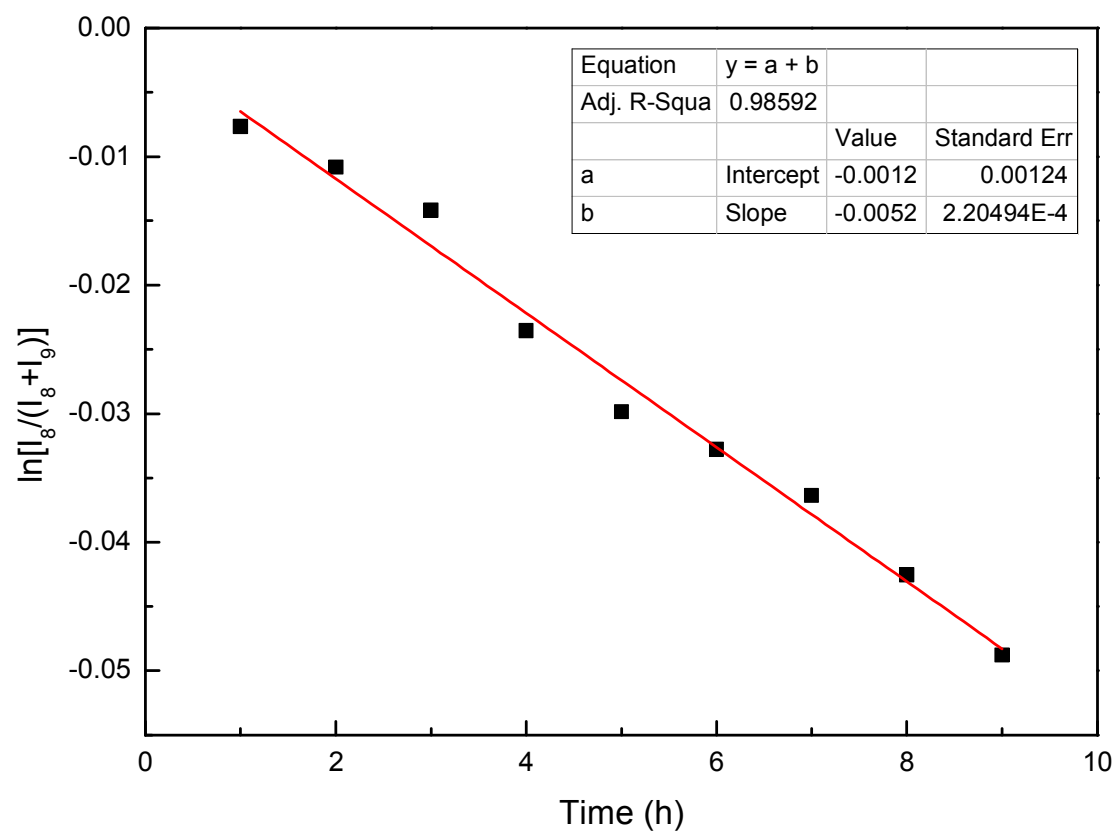

Figure S15. Plot of $\ln \left[I_{8} /\left(I_{8}+I_{9}\right)\right]$ vs time. 


\section{DFT Calculations}

All calculations were performed on an SGI Altix 450 server using the Gaussian 03

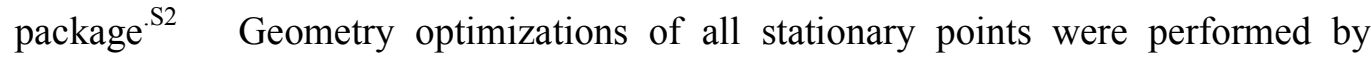
using the DFT method at the B3LYP level using the basis sets of 6-31G(d,p) for C, H, and $\mathrm{S}$ atoms + LanL2DZ for Sn. GaussView was used for visual inspection of the final geometries and vibrational frequencies as well as for drawing pictures of the optimized structures. All of the structures obtained herein were verified by examination of their Hessian matrix as minima (all frequencies real) or transition states (one imaginary frequency). Zero-point vibrational energies (ZPE) were incorporated into the total energies without a scale factor. At every transition state, the transition vector was animated with the GaussView program, and if necessary, the intrinsic reaction coordinate (IRC) was computed to connect the corresponding minima.

The DFT calculations were performed for the following compounds $8,9,8^{\prime}, 9^{\prime}, \mathbf{8}^{\prime \prime}$, and 9", and stationary points appeared during the reaction of 1' with $\mathrm{CS}_{2}$.

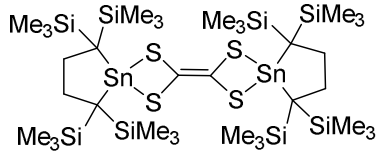

8

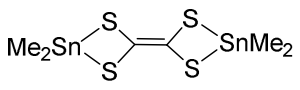

8'

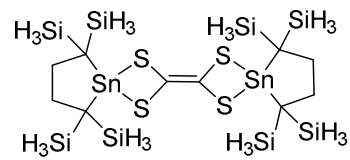

8"

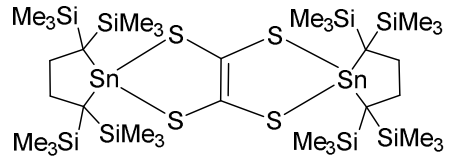

9

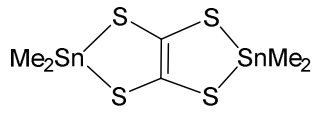

9'

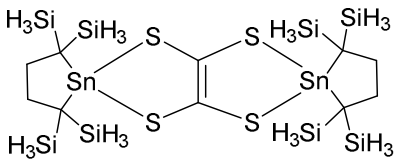

9"

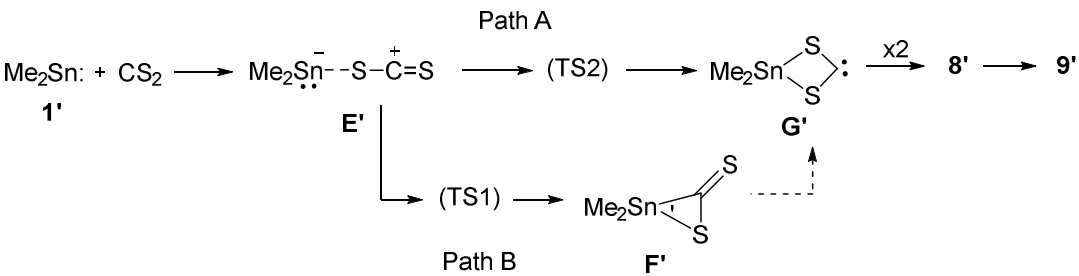


Table S2. Relative Energy Parameters for Species Shown in Chart S1 Calculated at the B3LYP/6-31G(d,p) for C, H, S atoms and LanL2DZ for Sn at 298.15K

\begin{tabular}{|c|c|c|c|c|}
\hline & $\Delta E^{\mathrm{a}}$ & $\Delta H^{\mathrm{a}}$ & $\Delta G^{\mathrm{a}}$ & $\Delta S^{b}$ \\
\hline 8 & $\underline{0.0}$ & $\underline{0.0}$ & $\underline{0.0}$ & $\underline{0.0}$ \\
\hline 9 & -12.8 & -12.9 & -13.0 & -0.4 \\
\hline $8^{\prime}$ & $\underline{0.0}$ & $\underline{0.0}$ & $\underline{0.0}$ & $\underline{0.0}$ \\
\hline 9', & -15.4 & -16.0 & -13.5 & -8.2 \\
\hline 8" & $\underline{0.0}$ & $\underline{0.0}$ & $\underline{0.0}$ & $\underline{0.0}$ \\
\hline 9" & -15.1 & -15.2 & -15.3 & 0.3 \\
\hline $\mathbf{1}^{\prime}+\mathrm{CS}_{2}$ & $\underline{0.0}$ & $\underline{0.0}$ & $\underline{0.0}$ & $\underline{0.0}$ \\
\hline $\mathbf{E}^{\prime}$ & 3.3 & 3.3 & 11.8 & -28.5 \\
\hline $\mathrm{F}^{\prime}$ & 6.0 & 5.9 & 16.4 & -35.1 \\
\hline G' & 20.1 & 20.2 & 29.9 & -32.6 \\
\hline TS1 & 10.1 & 9.8 & 20.4 & -35.6 \\
\hline TS2 & 20.6 & 19.9 & 31.2 & -37.7 \\
\hline$(1 / 2) 8^{\prime}$ & -55.7 & -56.2 & -21.7 & -115.9 \\
\hline$(1 / 2) 9^{\prime}$ & -71.1 & -72.2 & -35.2 & -124.1 \\
\hline
\end{tabular}

a. in kcal.mol ${ }^{-1} ;$ b. in cal.mol ${ }^{-1} \cdot \mathrm{K}^{-1}$

\section{References}

(S1) (a) C. L. Picou, E. D. Stevens, M. Shah, J. H. Boyer, Acta Crystallogr. Sect. C 1990, 46, 1148. (b) SMART, SAINT, SADABS and SHELXTL, Bruker AXS Inc., Madison, 2000.

(S2) Gaussian 03 (Revision D.01), M. J. Frisch, G. W. Trucks, H. B. Schlegel, G. E. Scuseria, M. A. Robb, J. R. Cheeseman, J. A. Montgomery, Jr., T. Vreven, K. N. Kudin, J. C. Burant, J. M. Millam, S. S. Iyengar, J. Tomasi, V. Barone, B. Mennucci, M. Cossi, G. Scalmani, N. Rega, G. A. Petersson, H. Nakatsuji, M. Hada, M. Ehara, K. Toyota, R. Fukuda, J. Hasegawa, M. Ishida, T. Nakajima, Y. Honda, O. Kitao, H. Nakai, M. Klene, X. Li, J. E. Knox, H. P. Hratchian, J. B. Cross, V. Bakken, C. Adamo, J. Jaramillo, R. Gomperts, R. E. Stratmann, O. Yazyev, A. J. Austin, R. Cammi, C. Pomelli, J. W. Ochterski, P. Y. Ayala, K. Morokuma, G. A. Voth, P. Salvador, J. J. Dannenberg, V. G. Zakrzewski, S. Dapprich, A. D. Daniels, M. C. Strain, O. Farkas, D. K. Malick, A. D. Rabuck, K. Raghavachari, J. B. Foresman, J. V. Ortiz, Q. Cui, A. G. Baboul, S. Clifford, J. Cioslowski, B. B. Stefanov, G. Liu, A. Liashenko, P. Piskorz, I. Komaromi, R. L. Martin, D. J. Fox, T. Keith, M. A. Al-Laham, C. Y. Peng, A. Nanayakkara, M. Challacombe, P. M. W. Gill, B. Johnson, W. Chen, M. W. Wong, C. Gonzalez, and J. A. Pople, Gaussian, Inc., Wallingford CT, 2004. 